Article

\title{
Preparation and Evaluation of the Tensile Characteristics of Carbon Fiber Rod Reinforced 3D Printed Thermoplastic Composites
}

\author{
Arivazhagan Selvam ${ }^{1, *}$, Suresh Mayilswamy ${ }^{2}$, Ruban Whenish ${ }^{3}\left(\mathbb{D}\right.$, Rajkumar Velu $^{4, *}$ (i) \\ and Bharath Subramanian ${ }^{3}$ \\ 1 Department of Mechanical Engineering, SCAD Institute of Technology, Coimbatore 641664, India \\ 2 Department of Robotics and Automation Engineering, PSG College of Technology, Coimbatore 641004, India; \\ kvm.suresh@gmail.com \\ 3 Department of Mechanical Engineering, Sri Krishna College of Technology, Coimbatore 641042, India; \\ wruban1990@gmail.com (R.W.); bharathsubramaniyan1497@gmail.com (B.S.) \\ 4 Centre for Laser Aided Intelligent Manufacturing, University of Michigan, Ann Arbor, MI 48109, USA \\ * Correspondence: arivuazhagan001@gmail.com (A.S.); rajkumar7.v@gmail.com (R.V.)
}

Citation: Selvam, A.; Mayilswamy,

S.; Whenish, R.; Velu, R.;

Subramanian, B. Preparation and

Evaluation of the Tensile

Characteristics of Carbon Fiber Rod Reinforced 3D Printed Thermoplastic Composites. J. Compos. Sci. 2021, 5, 8 https://doi.org/10.3390/jcs5010008

Received: 20 October 2020

Accepted: 24 December 2020

Published: 31 December 2020

Publisher's Note: MDPI stays neutral with regard to jurisdictional clai$\mathrm{ms}$ in published maps and institutional affiliations.

Copyright: $\odot 2020$ by the authors. Licensee MDPI, Basel, Switzerland. This article is an open access article distributed under the terms and conditions of the Creative Commons Attribution (CC BY) license (https:// creativecommons.org/licenses/by/ $4.0 /)$.

\begin{abstract}
The most common method to fabricate both simple and complex structures in the additive manufacturing process is fused deposition modeling (FDM). Many researchers have studied the strengthening of FDM components by adding short carbon fibers (CF) or by reinforcing solid carbon fiber rods. In the current research, we sought to enhance the mechanical properties of FDM components by adding bioinspired solid CF rods during the fabrication process. An effective bonding interface of bioinspired CF rods and polylactic acid (PLA) was achieved by triangular interlocking sutures and by employing synthetic glue as the binding agent. In particular, the tensile strength of solid CF rod reinforced PLA samples was studied. Critical parameters such as layer thickness, extruder temperature, extruder speed, and shell thickness were considered for optimization. Significant process parameters were identified through leverage plots using the response surface methodology (RSM). The optimum parameters were found to be layer thickness of $0.04 \mathrm{~mm}$, extruder temperature of $215^{\circ} \mathrm{C}$, extruder speed of $60 \mathrm{~mm} / \mathrm{s}$, and shell thickness of $1.2 \mathrm{~mm}$. The results revealed that the bioinspired solid CF rod reinforced PLA (CFRPLA) composite exhibited a tensile strength of $82.06 \mathrm{MPa}$, which was approximately three times higher than the pure PLA (28 MPa, $66 \%$ lower than CFRPLA), acrylonitrile butadiene styrene (ABS) (28 MPa, 66\% lower than CFRPLA), polyethylene terephthalate glycol (PETG) (34 MPa, 60\% lower than CFRPLA), and nylon (34 MPa, 60\% lower than CFRPLA) samples.
\end{abstract}

Keywords: CF rod reinforced PLA (CFRPLA); solid carbon fiber rod; fused deposition modeling (FDM); process parameters; tensile strength

\section{Introduction}

Additive manufacturing (AM) has brought the next industrial revolution in many key areas, such as aerospace, medicine, and automotive. The extensive usage of AM has widened to technologies applied in biomedical implants, architecture, and full-body organs using materials such as polymers, metals, composites, ceramics, wood, etc. [1,2]. Fused deposition modeling (FDM) is one of the simplest and most commonly used technologies in AM. Different types of polymers are used for building 3D objects as per computeraided design (CAD) by adding one layer over another with specified process parameters. The quality of the printed polymer objects depends on various process parameters, such as the printing material and part orientation during printing. These parameters influence the mechanical characteristics, building time, and volume, which affect the final cost of the part [3,4]. FDM-based fabricated components play a key role in medical, automotive, 
and aerospace applications due to their simplicity and cost-effectiveness. Polylactic acid (PLA) is widely used as a processing material in FDM technology due to its desirable characteristics and biocompatibility. Most of the research work carried out with pure PLA and PLA composites have become the hotspot in 3D printing [5]. In their research, Cicala et al. selected three PLA-based commercial filaments to study the influence of the mechanical properties of FDM specimens. A comparative approach was taken to differentiate pure PLA vs. PLA with added mineral fillers in order to identify better mechanical properties and printing quality. The mineral fillers dispersed in the filament improved the tensile properties of the printed specimens compared to pure PLA [6]. However, the strength of the pure thermoplastic components fabricated by the FDM process is comparatively low, which has significant limitations and restricts the application of $3 \mathrm{D}$ printed parts as functional components [7]. To overcome these limitations, researchers have recently shifted their focus toward dispersing additives in neat polymers to enhance their properties. Plain polymers produced via 3D printing have limited physicochemical properties. These properties can be improved by introducing fibers or particles along with the polymer matrix. In his study, Blanco showed how these reinforced polymers possessed better properties and could be associated with many fields of application [8]. Similarly, the strength of 3D printing samples was found to increase with the addition of short fibers when compared to samples without fiber reinforcement $[9,10]$. The mechanical properties and strength of thermoplastics such as acrylonitrile butadiene styrene (ABS) and polyamide- 6 produced through FDM was improved by reinforcing different modifiers like plasticizers and short glass fiber [11,12].

Hao et al. analyzed the bending interlaminar strength and lifetime of carbon/epoxy laminated curved beams using the digital speckle correlation method (DSCM) with a fourpoint bending test configuration by varying the thickness and radius/thickness ratio. The bending interlaminar strength of carbon/epoxy laminated curved beams were analyzed by ultrasonic $\mathrm{C}$-scan images. The failure strength and maximum interlaminar radial stresses of carbon/epoxy laminated curved beams were found when deformation occurred by applying delamination mechanisms $[13,14]$. Ruban et al. carried out an experiment on the effect of process parameters such as layer thickness, hatch spacing, laser power, and part bed temperature for Laserform stainless steel (ST-100) by adopting the selective laser sintering (SLS) technology. It was observed that better mechanical properties were obtained when the layer thickness was kept as $0.08 \mathrm{~mm}$ [15]. Zeng et al. fabricated wood-plastic composite (WPC) parts using SLS. They analyzed the relationship between laser intensity and WPC parts. When the laser intensity increased from 226 to $311 \mathrm{~W} / \mathrm{mm}^{2}$, the tensile strength improved by $191 \%$ and the bending strength improved by $17 \%$. However, when the laser intensity exceeded $340 \mathrm{~W} / \mathrm{mm}^{2}$, both the tensile and bending strength decreased [16]. Gray studied polypropylene (PP) thermoplastic material reinforced with thermotropic liquid crystalline polymer (TLCP) fibrils produced by the dual extruder process in FDM technology. The melting point of PP was $165^{\circ} \mathrm{C}$, whereas it was $283^{\circ} \mathrm{C}$ for TLCP fibrils. TLCP has long and short fibers, and both were reinforced with PP and produced separately. With respect to mechanical properties, long TLCP fibers were found to have better tensile properties than short TLCP fibers [17]. Fischer et al. designed and developed a nozzle-type 3D fiber print head to produce a polymer matrix composite layer by layer [18]. Melenka et al. fabricated 3D printed structures reinforced with continuous carbon, fiberglass, or Kevlar fibers and evaluated the elastic properties using the volume average stiffness (VAS) method. The fibers were added to the matrix in different volume fractions, and the difference between experimental and predicted elastic properties was identified. This method helped researchers design the functional components to choose the right combination of matrix and reinforcement [19]. Christ et al. analyzed the green strength of large and fragile printed structures while performing the depowdering procedure in a powder bed. By reinforcing different short fibers with the polymer matrix of cellulose-modified gypsum powder, the binding strength increased by about $180 \%$, which added much strength and avoided collapse of the printed green structures, while the work of fracture values was 10 times higher [20]. Considering the bonding interface between carbon fiber (CF) and 
PLA resin produced by the FDM process, Li et al. designed a nozzle to mix uniformly continuous CF with PLA. The printed part had less bonding interface between CF and PLA, and continuous CF was preprocessed and added to the PLA resin, which improved the tensile and flexural strength of composites by $13.8 \%$ and $164 \%$, respectively [21].

Ćwikła et al. investigated the influence of printing parameters on the mechanical properties of ABS produced through FDM technology. Infill pattern, infill density, shell thickness, printing temperature, and the type of material were selected as parameters, and the samples were tested for a honeycomb pattern. Infill density of about $40-50 \%$ and shell thickness of 2-3 layers/line were found to be better parameters considering the strength of the printed pattern [22]. In their experiment, Ning et al. evaluated the effect of process parameters such as raster angle, layer thickness, infill speed, and nozzle temperature for producing carbon fiber reinforced plastics (CFRP) using FDM technology. Raster angle and infill speed had a significant influence on the tensile characteristics of the printed parts, while a layer thickness of $0.15 \mathrm{~mm}$ produced good tensile properties [23,24]. Another study by Tian et al. analyzed carbon fiber reinforced PLA (CFRPLA) produced by the FDM process considering critical process parameters such as temperature and pressure. The optimized bonding strength between layers was achieved using optimized process parameters such as a layer thickness of $0.4-0.6 \mathrm{~mm}$, hatch spacing of $0.6 \mathrm{~mm}$, and temperature of $200-230{ }^{\circ} \mathrm{C}$. The maximum flexural strength of $335 \mathrm{MPa}$ and flexural modulus of $30 \mathrm{GPa}$ was achieved when the fiber content of the composite specimens was $27 \%$ [25]. Lin et al. analyzed process parameters such as tip angle and bonded tip region presence/absence as well as geometries such as trapezoidal, rectangular, triangle, and antitrapezoidal for 3D printed polymer sutures. Triangular sutures exhibited uniform stress distribution throughout the structure, with the teeth areas especially possessing better mechanical properties. The experimental results and analytical models of 3D printed sutures showed excellent agreement [26]. Padzi et al. did a comparative study on the suitability of ABS produced by FDM for industrial applications. ABS with a dog bone shape was produced by FDM or a molding process as per the ASTM D638 standard. Fatigue tests were carried out at 40,60 , and $80 \%$ tensile strength. The results showed that ABS produced through 3D printing had lower fatigue life than through the molding process, indicating its suitability for low-strength applications [27]. Changes in process parameters and addition of composites might increase the strength of ABS prototypes produced by FDM $[28,29]$. Wu optimized the process parameters of FDM by designing a cylindrical model. Parameters such as slice height, printing time, consumables, and dimensional accuracy were optimized, and the results showed that a slice height of $0.14 \mathrm{~mm}$ reduced the printing time without sacrificing the quality of printing [30]. Srinivasan et al. examined the influence of infill density on the tensile characteristics of polyethylene terephthalate glycol (PETG) and ABS by FDM technology. Specimens were printed by maintaining the other parameters as constant but varying the infill density levels. It was observed that the infill density had a considerable influence on the tensile strength of the PETG and ABS parts [31-33].

Selvam et al. discussed ways to improve the strength of 3D printed bioinspired interlock sutures made up of PLA reinforced CF by particle swarm optimization (PSO). The strength of 3D printed sutures was highly influenced by building parameters such as printing speed, layer thickness, and temperature. It was observed that a printing speed of $60 \mathrm{~mm} / \mathrm{s}$, layer thickness of $0.1 \mathrm{~mm}$, and temperature of $190^{\circ} \mathrm{C}$ yielded maximum strength outcomes [34]. Dey et al. studied the tensile properties of ABS and PLA material reinforced with fibers produced by FDM technology and found that they were highly influenced by layer thickness, extruder speed, raster angle, extruder temperature, and shell thickness [35].

In the aforementioned literature, researchers reinforced short fibers or continuous fibers during the fabrication process to improve the strength of 3D printed components. Instead of reinforcing fibers during the fabrication process, this research focused on inserting solid bioinspired carbon fiber rods into the sample after the fabrication process. In addition, triangular-shaped interlock suture from a stickleback fish pelvic girdle was 
biomimicked and applied to the CF rod and PLA sample. The maximum tensile strength was obtained with optimum process parameters of bioinspired 3D printed PLA using the response surface methodology (RSM) technique.

\section{Materials and Methods}

\subsection{Bioinspired Suture Selection}

Various biological structures of animals and plants can be mimicked to acquire unique properties with effective energy absorption capacity. The ancient sea ammonite shells are one of the best examples of suture interfaces that show various types of geometric profile starting from the basic curve to complicated fractal-like designs. Martin et al. referred to a bioinspired reinforced architecture created with 3D magnetic printing by combining additive technologies with discontinuous fibers, which delivered enhanced mechanical performance compared to the monolithic structure [36]. The suture interface geometry of the anatomy of different creatures was investigated and selected to design a solid carbon fiber rod with interlock sutures.

The triangular interlock sutures were inspired from the pelvic girdle of marine sticklebacks (fish). The three-spine marine sticklebacks protect themselves from predators with their biological armor structured body. The armor body of sticklebacks consists of the basal plate, spines, dorsal spines, lateral plates, and pelvic girdle. Many studies have been done on the structure of stickleback armor to develop bioinspired protective shields, vehicle body, building structures, protective coating, abrasion/rock penetration resistance pipelines, safety helmets, etc. The pelvic girdle of sticklebacks is made up of two ventral pelvic plates joined together by a triangular interlocking suture. Many researchers have used different bioinspired types of sutures like antitrapezoidal, rectangular, sawtooth, jigsaw, and triangular to enhance the mechanical properties of FDM components [37]. These studies reveal that, compared to other interlock sutures, triangular geometry sutures have a simple design and are more effective as they have superior tensile strength, stiffness, flexural strength, and toughness. From the above observation, a triangular-shaped suture was made manually on a plain carbon fiber rod using a specialized triangular file, as shown in Figure 1. The triangular-shaped file tool had a three-sided design that could sharpen and make a saw teeth profile (triangular suture).

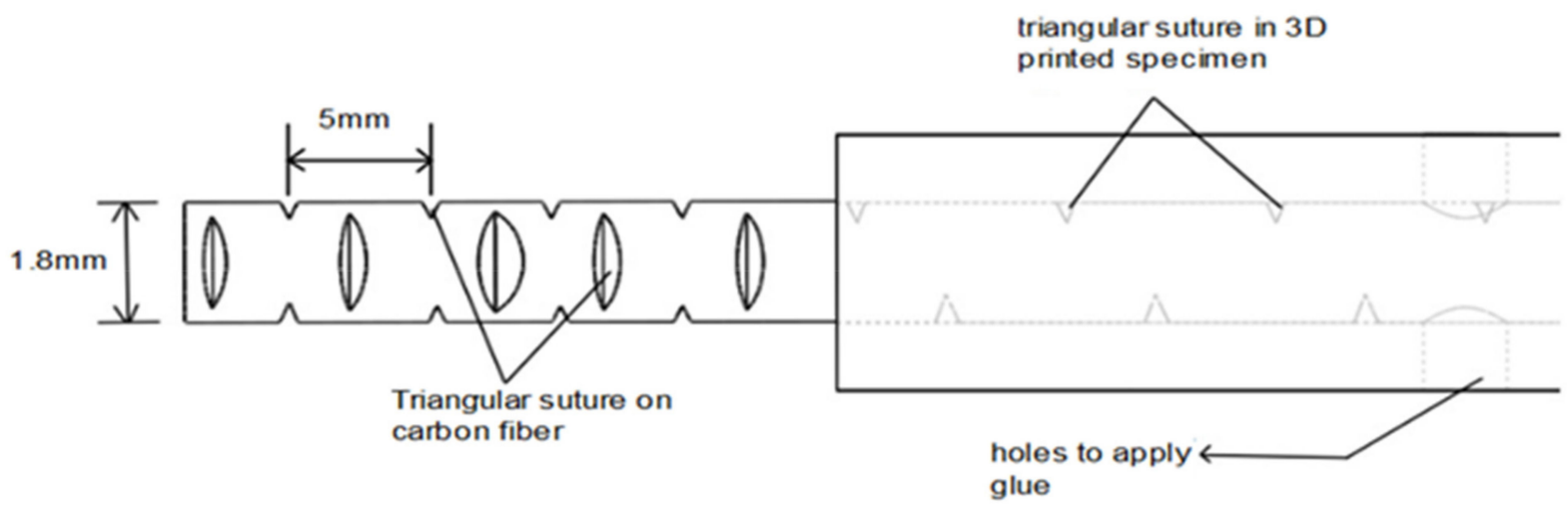

Figure 1. Solid carbon fiber $(\mathrm{CF})$ rod and 3D printed specimen with triangular interlock sutures.

\subsection{Critical Process Parameters}

In the additive manufacturing process of solid CF rod reinforced FDM samples, there are various significant process parameters that influence and improve the mechanical properties. Based on the literature study, layer thickness, extruder temperature, extruder speed, and shell thickness were chosen as the parameters [33]. 


\subsection{Material Selection and Mechanical Property Investigation}

PLA was selected as a printing material for the interlocking suture due to its biodegradable nature, availability, and diverse properties. A short carbon fiber rod was employed with pure PLA to enhance the mechanical properties. The addition of CF as a composite material is not conventional, so a new approach was applied by employing CF as a solid rod. The properties of PLA and the CF material are mentioned in Table 1 below.

Table 1. Mechanical properties of polylactic acid (PLA) and carbon fiber rod.

\begin{tabular}{cc}
\hline Mechanical Properties of PLA & Mechanical Properties of Carbon Fiber Rod \\
\hline Tensile strength: $59 \mathrm{MPa}$ & Tensile strength: $3800 \mathrm{MPa}$ \\
Flexural strength: $106 \mathrm{MPa}$ & Density: $1.81 \mathrm{~g} / \mathrm{cm}^{3}$ \\
Elongation at break: $7.0 \%$ & Carbon content: $95 \%$ \\
Rockwell hardness: $88 \mathrm{HR}$ & Elastic modulus: $242 \mathrm{GPa}$ \\
\hline
\end{tabular}

\subsection{Specimen Fabrication and Use of Solid Carbon Rod}

A tensile specimen of pure PLA was designed with 3D modeling software and converted into STL format. The fabrication was initiated with reference process parameters that were chosen from various literatures. For the printing of pure PLA specimen, process parameters such as raster angle of $45^{\circ}$ and horizontal build orientation [33] were kept constant throughout the experiments as per ASTM D638-10 tensile test specimen, as shown in Figure 2. To increase the tensile strength of the fabricated reference sample, bioinspired solid CF rods of diameter $1.8 \mathrm{~mm}$ was reinforced manually into the three holes provided in the specimen. The inner surface of the holes was projected with a triangular suture. The interface bonding between the PLA and the CF rods were improved by applying adhesive (cyanoacrylate) through the holes exactly above the path of the solid CF rods. The process parameters mentioned in Table 2 were used to fabricate the pure PLA tensile specimen.

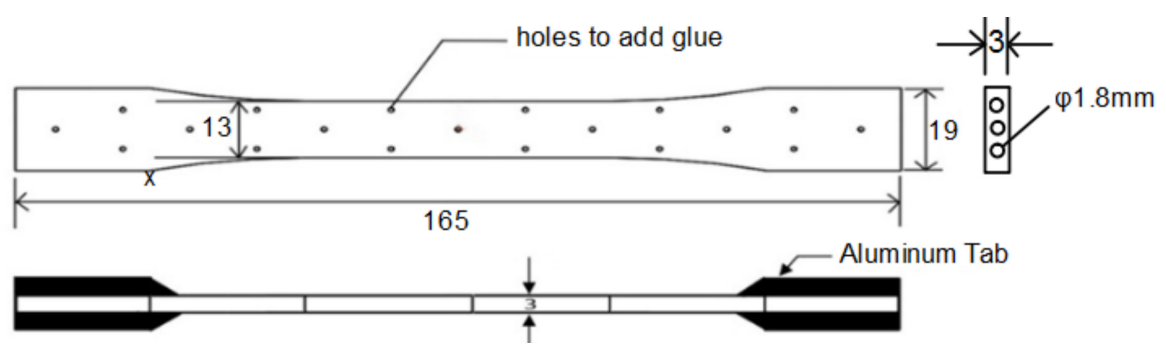

Figure 2. ASTM D638-10 tensile test specimen reinforced with solid carbon fiber rods.

Table 2. Reference sample parameters [29].

\begin{tabular}{ccccc}
\hline Layer Thickness (mm) & $\begin{array}{c}\text { Extruder } \\
\text { Temperature }\left({ }^{\circ} \mathbf{C}\right)\end{array}$ & Extruder Speed (mm/s) & Shell Thickness (mm) & Tensile Strength (MPa) \\
\hline 0.08 & 205 & 80 & 0.8 & 71.6 \\
\hline
\end{tabular}

If the thickness of the tensile specimen is $3 \mathrm{~mm}$, the diameter of the solid CF rod should be less than $3 \mathrm{~mm}$. At the same time, it should occupy more than $50 \%$ of the thickness of a tensile specimen in order to enhance the tensile strength and triangular suture characteristics. Solid CF rods are available in different diameters, but based on the above criteria, a rod diameter of $1.8 \mathrm{~mm}$, or $60 \%$ of the tensile specimen value, was selected. The plain solid CF rod was preprocessed by a triangular file with $60^{\circ}$ angle to generate triangular interlock sutures over the surface with a regular interval of $5 \mathrm{~mm}$. Next, the solid CF rod was inserted into the tensile specimen hole with the help of a plastic mallet (interference fit). The linear and angular movement of the solid carbon rod was arrested by pouring the glue into the holes on the tensile specimen surface as well as in the $1.8 \mathrm{~mm}$ hole. The bonding strength between the CF rod and the pure PLA tensile specimen was ensured 
by a bonding agent (cyanoacrylate). The flow ability of the bonding agent was higher and covered the whole inner surface of the tensile specimen. Hence, no other external force was needed to increase the bonding strength. The layer view of solid CFRPLA is presented in Figure 3. Figure 4 represents the raster angle of $45^{\circ}$, and Figure 5 illustrates the types of built orientation for fabricating tensile specimens.

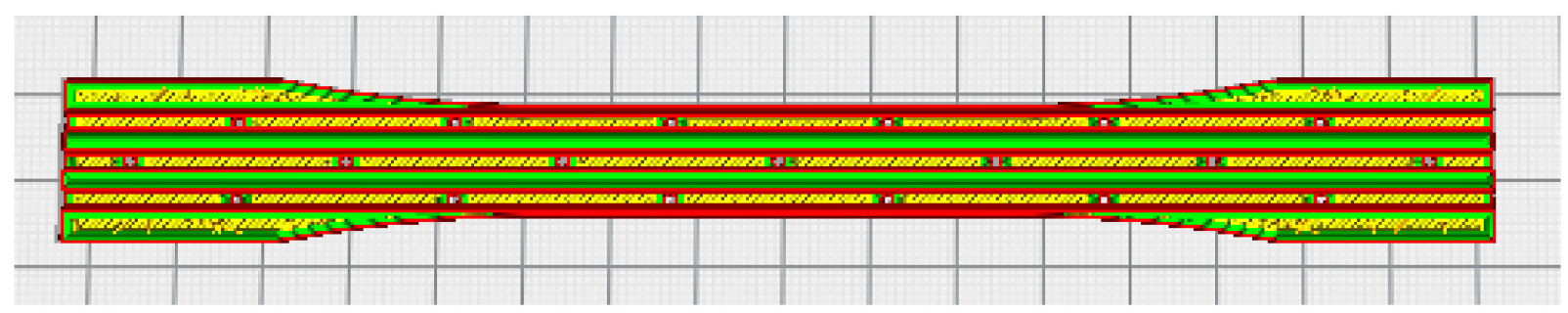

Figure 3. Layer view of solid CF rod reinforced with polylactic acid(PLA) specimen.

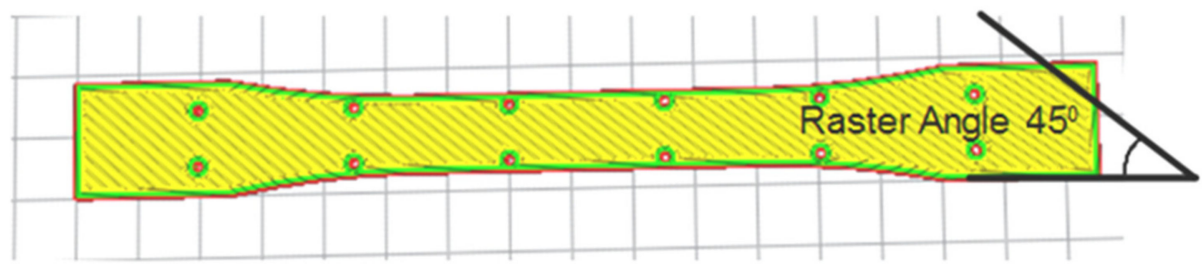

Figure 4. Raster angle.

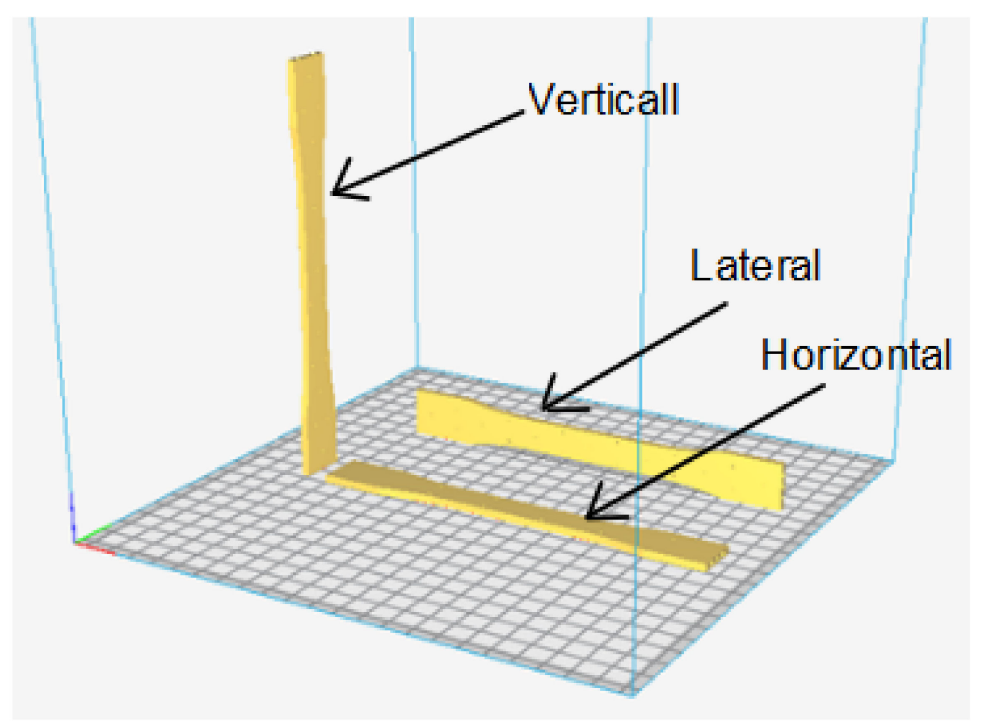

Figure 5. Built orientation.

\subsection{Tensile Testing of the CFRPLA Rod}

After the fabrication of pure PLA, it was employed with the CF rod using the binding agent. The tensile strength was measured to understand the mechanical behavior of PLA employed with the CF rod. The Autograph AG-Is $50 \mathrm{KN}$ machine was used for the tensile test. The tensile test for the specimen was carried out gradually at a jaw speed of $0.4 \mathrm{~mm} / \mathrm{s}$ until the specimen broke. An extensometer was employed to measure the strain. The tensile test was performed to measure the tensile strength of the reference sample and compare it with the pure PLA sample, as shown in Figure 6. The results showed that the tensile strength of bioinspired solid CF rod reinforced FDM samples was 2.5 times superior to 3D printed pure PLA samples. The Young's modulus (tensile modulus) of the CFRPLA was 
2.5 to 4 times higher than the plain PLA based on the stress-strain curve. Figure 7 shows the CFRPLA tensile specimen after the tensile test. To maximize the tensile strength of 3D printed components and determine the detailed relationship between each parameter and the tensile characteristics of specimens, a trial and error method was followed.

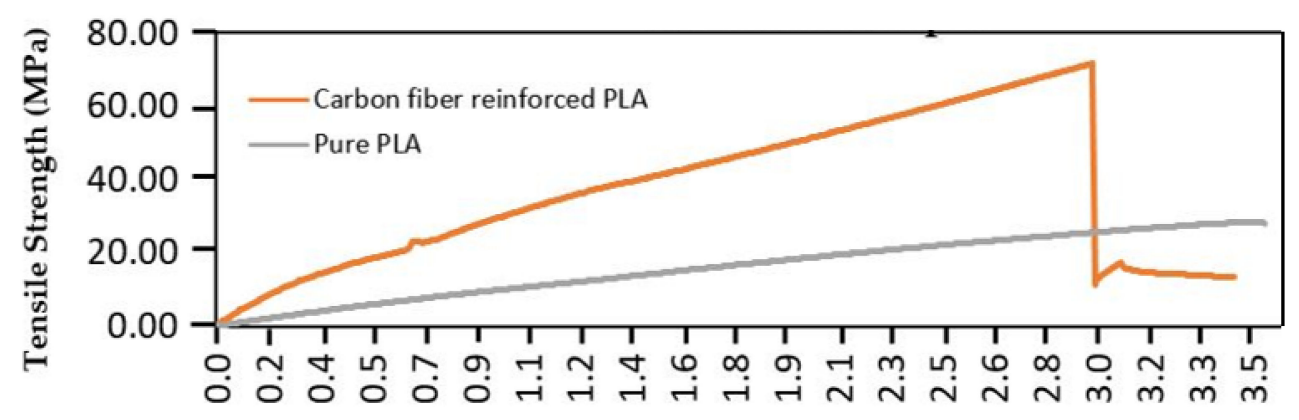

Strain

Figure 6. Pure PLA vs. carbon fiber reinforced specimen.

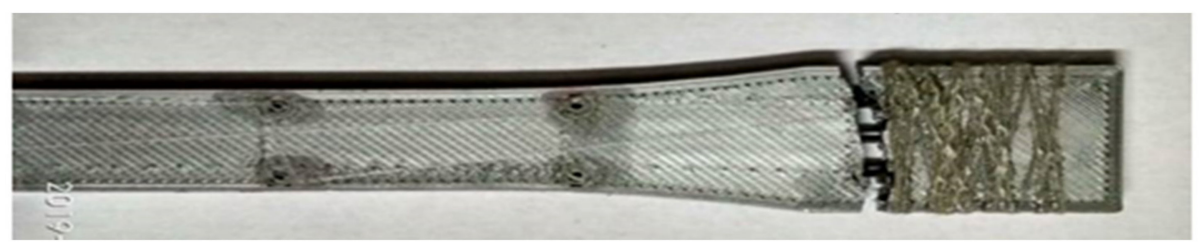

Figure 7. Tensile specimen of the CF rod reinforced PLA (CFRPLA) rod.

\subsubsection{Tensile Strength vs. Layer Thickness}

The effect of layer thickness was evaluated by fabricating five different samples of varying layer thickness ranging from 0.04 to $0.12 \mathrm{~mm}$, as specified in Table 3 . In the reference sample, the layer thickness was kept as $0.08 \mathrm{~mm}$ referring to the literature. In addition, two upper and two lower values with intervals of $0.02 \mathrm{~mm}$ were used. While fabricating the samples, the other four parameters were kept constant as mentioned in the reference sample. As shown in Figure 8, the sample printed with a layer thickness of $0.06 \mathrm{~mm}$ had the maximum tensile strength. From the above result, it can be concluded that the optimum layer thickness $0.06 \mathrm{~mm}$ would give the highest tensile strength for $\mathrm{CF}$ rod reinforced 3D printed samples.

Table 3. Tensile strength vs. layer thickness.

\begin{tabular}{lccccc}
\hline Layer thickness $(\mathrm{mm})$ & 0.04 & 0.06 & 0.08 & 0.1 & 0.12 \\
\hline Tensile strength $(\mathrm{MPa})$ & 69 & 72 & 71.6 & 68 & 67 \\
\hline
\end{tabular}



Figure 8. Tensile strength vs. layer thickness. 


\subsubsection{Tensile Strength vs. Extruder Temperature}

The effect of extruder temperature was investigated by fabricating five different samples with extruder temperature ranging from 195 to $215^{\circ} \mathrm{C}$, as specified in Table 4 . In addition to the sample specimen extruder temperature $205^{\circ} \mathrm{C}$, two upper and two lower values with intervals of $5{ }^{\circ} \mathrm{C}$ were used. While printing the samples, the previously obtained optimum layer thickness of $0.06 \mathrm{~mm}$ was used, and the remaining three parameter values mentioned in the reference sample were kept constant. As shown in Figure 9, the sample printed with the extruder temperature of $210{ }^{\circ} \mathrm{C}$ resulted in the highest tensile strength. From the above result, it was concluded that the optimum extruder temperature of $210^{\circ} \mathrm{C}$ would give the highest tensile strength compared to the other extruder temperatures.

Table 4. Tensile strength vs. extruder temperature.

\begin{tabular}{cccccc}
\hline Extruder temperature $\left({ }^{\circ} \mathrm{C}\right)$ & 195 & 200 & 205 & 210 & 215 \\
\hline Tensile strength $(\mathrm{MPa})$ & 65 & 70 & 72 & 74.6 & 74.1 \\
\hline
\end{tabular}

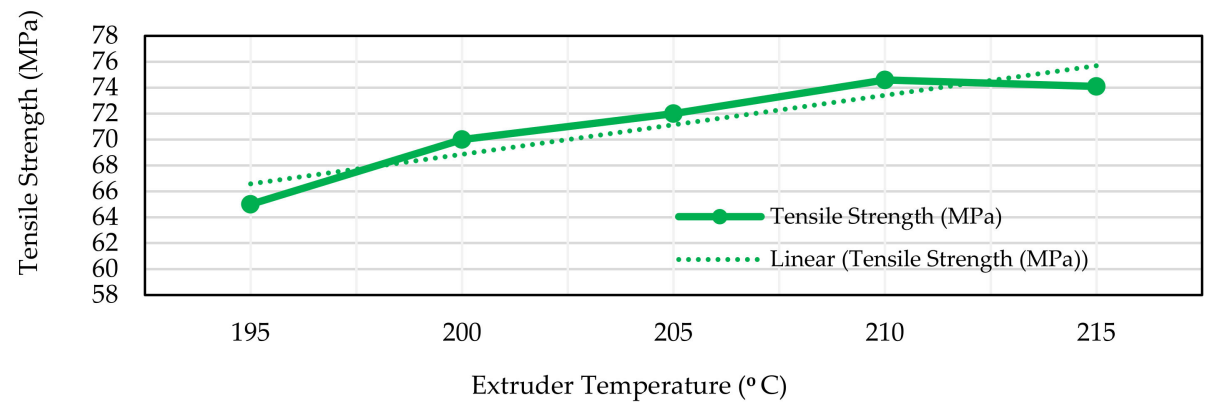

Figure 9. Tensile strength vs. extruder temperature.

\subsubsection{Tensile Strength vs. Extruder Speed}

The effect of extruder speed was investigated by fabricating five different samples with extruder speeds ranging from 60 to $100 \mathrm{~mm} / \mathrm{s}$, as specified in Table 5 . In addition to the sample specimen extruder speed of $80 \mathrm{~mm} / \mathrm{s}$, two upper and two lower values with intervals of $10 \mathrm{~mm} / \mathrm{s}$ were used. While printing the samples, the previously obtained optimum layer thickness of $0.06 \mathrm{~mm}$ and extruder temperature of $210^{\circ} \mathrm{C}$ were used, and the remaining two parameter values mentioned in the reference sample were kept constant. As shown in Figure 10, the tensile strength of the solid CF rod reinforced 3D printed sample was highest when the extruder speed was $60 \mathrm{~mm} / \mathrm{s}$. From the above result, it was concluded that the optimum extruder speed of $60 \mathrm{~mm} / \mathrm{s}$ would give the highest tensile strength of solid CF rod reinforced 3D printed samples.

Table 5. Tensile strength vs. extruder speed.

\begin{tabular}{cccccc}
\hline Extruder speed $(\mathrm{mm} / \mathrm{s})$ & 60 & 70 & 80 & 90 & 100 \\
\hline Tensile strength $(\mathrm{MPa})$ & 76.1 & 75.6 & 74.5 & 72 & 70 \\
\hline
\end{tabular}

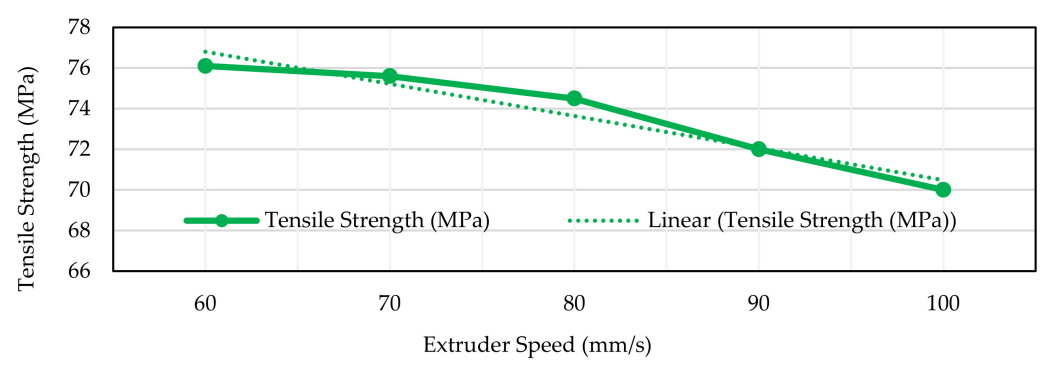

Figure 10. Tensile strength vs. extruder speed. 


\subsubsection{Tensile Strength vs. Shell Thickness}

The effect of shell thickness was investigated by fabricating five different samples with shell thickness ranging from 0.4 to $1.2 \mathrm{~mm}$, as specified in Table 6 . In addition to the sample specimen shell thickness of $0.8 \mathrm{~mm}$. two upper and two lower values with intervals of $0.2 \mathrm{~mm}$ were used. While printing the samples, the previously obtained optimum parameter values, i.e., layer thickness of $0.06 \mathrm{~mm}$, extruder temperature of $210^{\circ} \mathrm{C}$, and extruder speed of $60 \mathrm{~mm} / \mathrm{s}$, were used, and the remaining one parameter mentioned in the reference sample was kept constant. As shown in Figure 11, the tensile strength was enhanced when the sample was printed with a shell thickness of $1.2 \mathrm{~mm}$. From the above result, it was concluded that the optimum shell thickness of $1.2 \mathrm{~mm}$ would give the highest tensile strength.

Table 6. Tensile strength vs. shell thickness.

\begin{tabular}{cccccc}
\hline Shell thickness $(\mathrm{mm})$ & 0.4 & 0.6 & 0.8 & 1 & 1.2 \\
\hline Tensile strength $(\mathrm{MPa})$ & 71.4 & 72.8 & 74.6 & 76.1 & 78.8 \\
\hline
\end{tabular}

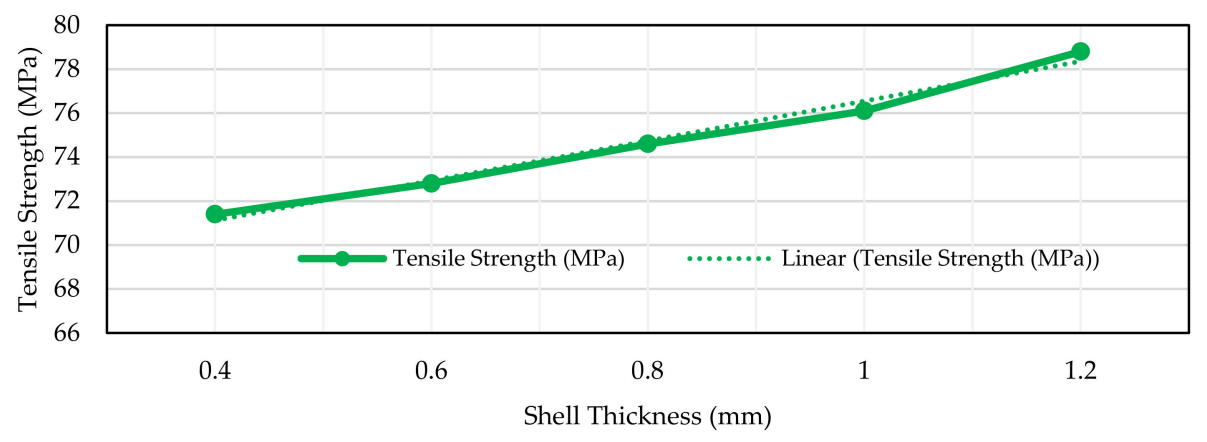

Figure 11. Tensile strength vs. shell thickness.

Based on the experimental results, the process parameters and tensile strength values of each specimen was validated analytically with RSM. The optimum parameters and their influence could be identified and evaluated based on the experimental results, as shown in Table 7.

Table 7. Tensile measurement.

\begin{tabular}{|c|c|c|c|c|c|}
\hline Experimental Runs & $\begin{array}{l}\text { Layer Thickness } \\
\text { (mm) }\end{array}$ & $\begin{array}{c}\text { Extruder } \\
\text { Temperature }\left({ }^{\circ} \mathrm{C}\right)\end{array}$ & $\begin{array}{l}\text { Extruder Speed } \\
\quad(\mathrm{mm} / \mathrm{s})\end{array}$ & $\begin{array}{l}\text { Shell Thickness } \\
\text { (mm) }\end{array}$ & $\begin{array}{l}\text { Tensile Strength } \\
\text { (MPa) }\end{array}$ \\
\hline 1 & 0.08 & 205 & 80 & 0.8 & 71.6 \\
\hline 2 & 0.04 & 205 & 80 & 0.8 & 69 \\
\hline 3 & 0.06 & 205 & 80 & 0.8 & 72 \\
\hline 4 & 0.08 & 205 & 80 & 0.8 & 71.6 \\
\hline 5 & 0.1 & 205 & 80 & 0.8 & 68 \\
\hline 6 & 0.12 & 205 & 80 & 0.8 & 67 \\
\hline 7 & 0.06 & 195 & 80 & 0.8 & 65 \\
\hline 8 & 0.06 & 200 & 80 & 0.8 & 70 \\
\hline 9 & 0.06 & 205 & 80 & 0.8 & 72 \\
\hline 10 & 0.06 & 210 & 80 & 0.8 & 74.6 \\
\hline 11 & 0.06 & 215 & 80 & 0.8 & 74.1 \\
\hline 12 & 0.06 & 210 & 60 & 0.8 & 76.1 \\
\hline 13 & 0.06 & 210 & 70 & 0.8 & 75.6 \\
\hline 14 & 0.06 & 210 & 80 & 0.8 & 74.5 \\
\hline 15 & 0.06 & 210 & 90 & 0.8 & 72 \\
\hline 16 & 0.06 & 210 & 100 & 0.8 & 70 \\
\hline 17 & 0.06 & 210 & 60 & 0.4 & 71.4 \\
\hline 18 & 0.06 & 210 & 60 & 0.6 & 72.8 \\
\hline 19 & 0.06 & 210 & 60 & 0.8 & 74.6 \\
\hline 20 & 0.06 & 210 & 60 & 1 & 76.1 \\
\hline 21 & 0.06 & 210 & 60 & 1.2 & 78.8 \\
\hline
\end{tabular}




\subsubsection{Mathematical Model}

From the experimental data depicted in Tables 8 and 9, a regression model was developed using JMP (John's Macintosh Project) software version 15, 2019. JMP was used in this research for the design of experiments (DOE) and reliability modeling of CFRPLA based on the tensile characteristics. The tensile strength of CFRPLA with respect to the significant process parameters were expressed with the general regression model, as shown in Equation (1).

$$
y=y-\varepsilon=b 0 \times 0+b 1 \times 1+b 2 \times 2+b 3 \times 3+b 4 \times 4
$$

Table 8. Parameter estimates.

\begin{tabular}{ccccc}
\hline Term & Estimate & Std Error & t Ratio & Prob > ItI \\
\hline Intercept & -17.684 & 17.071 & -1.04 & 0.316 \\
Layer thickness $(\mathrm{mm})$ & -44.529 & 19.480 & -2.29 & 0.036 \\
Extruder temperature $\left({ }^{\circ} \mathrm{C}\right)$ & 0.451 & 0.077 & 5.83 & $<0.0001$ \\
Extruder speed $(\mathrm{mm} / \mathrm{s})$ & -0.105 & 0.030 & -3.53 & 0.003 \\
Shell thickness $(\mathrm{mm})$ & 9.05 & 2.272 & 3.98 & 0.001 \\
\hline
\end{tabular}

Table 9. Analysis of variance.

\begin{tabular}{ccccc}
\hline Source & DF & Sum of Squares & Mean Square & F Ratio \\
\hline Model & 4 & 191.195 & 47.799 & 23.155 \\
Error & 16 & 33.028 & 2.064 & Prod $>$ F \\
C. Total & 20 & 224.223 & & $<0.0001$ \\
\hline
\end{tabular}

From the above table, the coefficient of each parameter was substituted in the general regression Equation (1) to develop the mathematical model to predict the optimum process parameter values to maximize the tensile strength.

$$
-17.684-44.5 \times 1+0.450 \times 2-0.105 \times 3+9.05 \times 4=\text { Tensile Strength }
$$

From the above relationship between the tensile strength of predicted value vs. actual value, the $R^{2}$ value of tensile strength was found to be 0.85 . A $p$-value $<0.0001$ was used to indicate the significance and influence of process parameters on the tensile characteristic of CFRPLA. The plot between actual tensile strength vs. predicted value is shown in Figure 12.

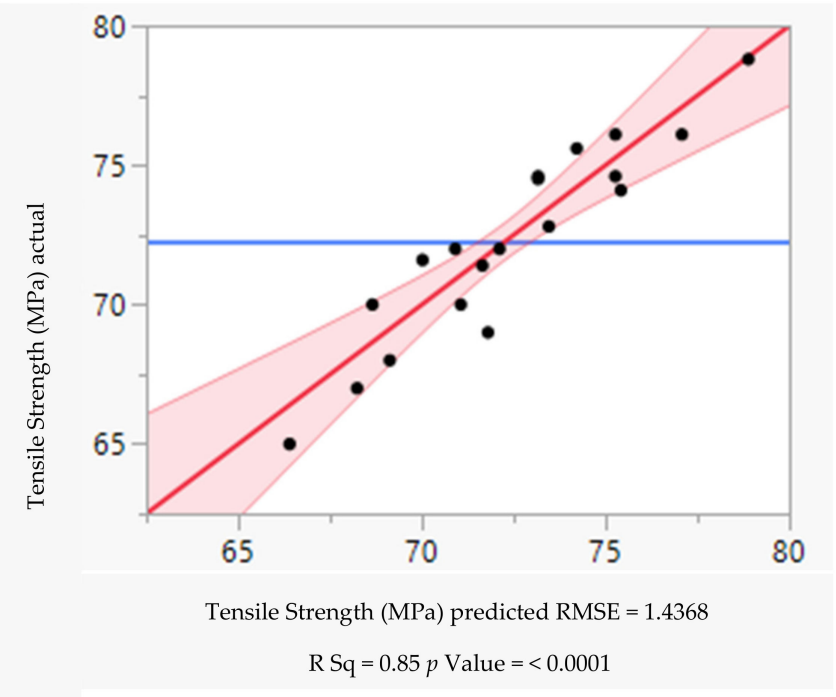

Figure 12. Actual tensile strength vs. predicted value. 


\section{Result and Discussion}

\subsection{Influence of Process Parameters on Tensile Strength}

The influence of each parameter on the tensile strength of CFRPLA was evaluated by a leverage plot. The $p$-value of each parameter revealed how the parameter influenced the tensile strength.

\subsection{Leverage Plot of Layer Thickness vs. Tensile Strength}

The plot in Figure 13 shows that $p=0.036$, which is greater than 0.005 , indicating that layer thickness was not a highly significant process parameter.

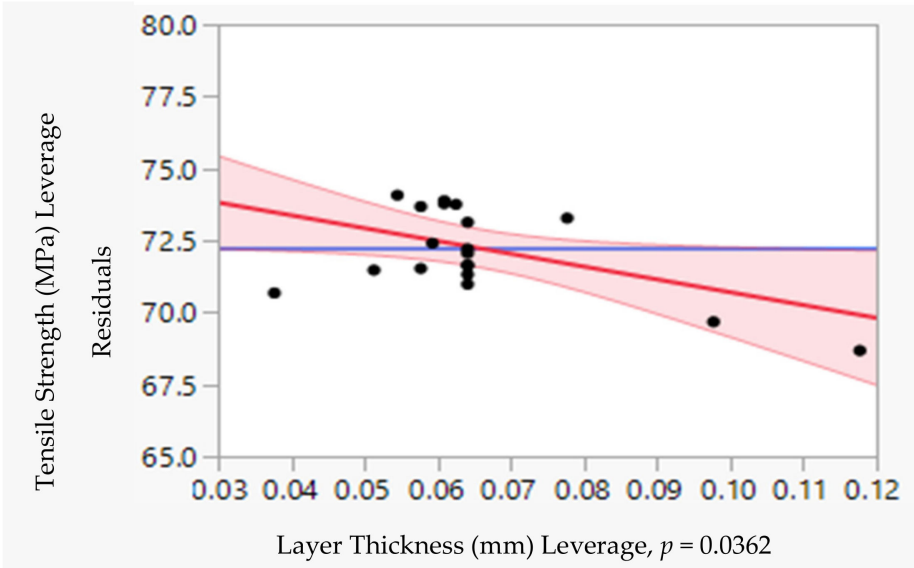

Figure 13. Tensile strength vs. layer thickness.

\subsection{Leverage Plot of Extruder Temperature vs. Tensile Strength}

The plot in Figure 14 shows $p<0.0001$, which is less than 0.005 , indicating that extruder temperature was a highly significant process parameter.

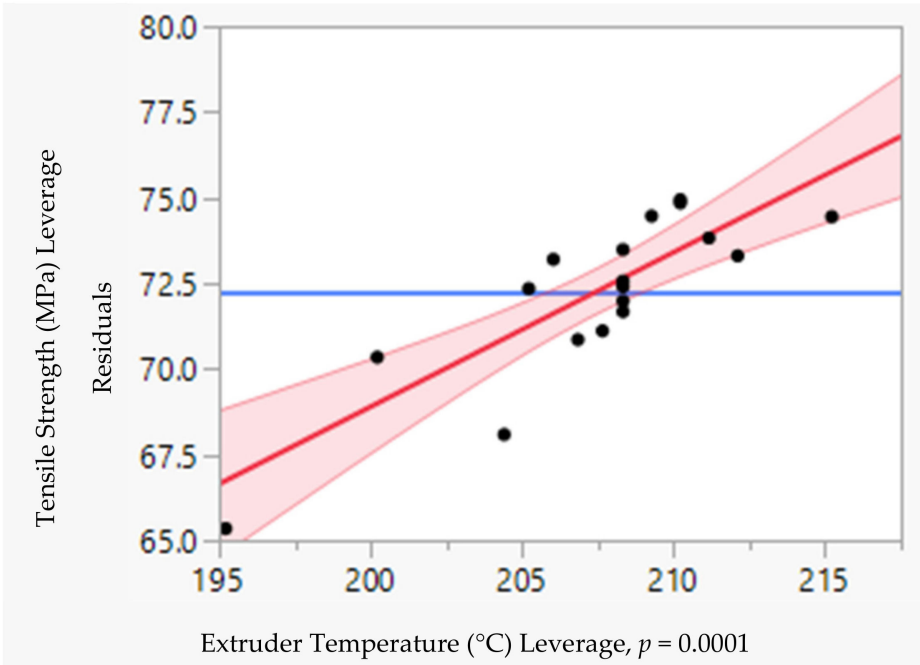

Figure 14. Tensile strength vs. extruder temperature.

\subsection{Leverage Plot of Extruder Speed vs. Tensile Strength}

The plot in Figure 15 shows that $p=0.003$, which is less than 0.005 , indicating that extruder speed was a highly significant process parameter. 


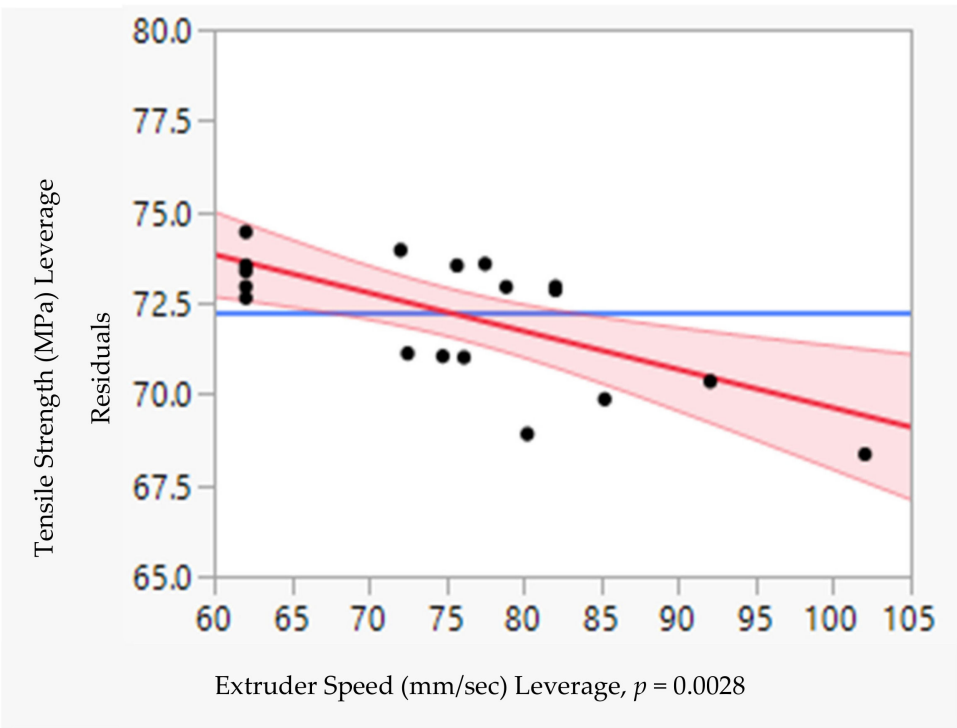

Figure 15. Tensile strength vs. extruder speed.

\subsection{Leverage Plot of Shell Thickness vs. Tensile Strength}

The plot in Figure 16 shows $p=0.001$, which is less than 0.005 , indicating that shell thickness was a highly significant process parameter.

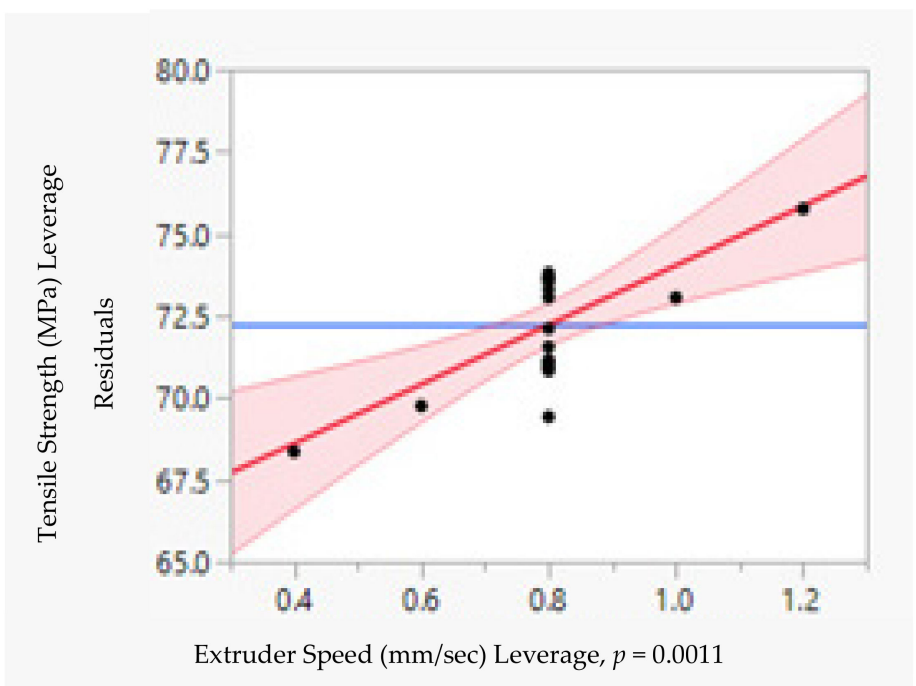

Figure 16. Tensile Strength vs. Shell Thickness.

From the leverage plots, the $p$-value for each process parameters was obtained to determine their significance. The extruder temperature, extruder speed, and shell thickness highly influenced the tensile strength of the CFRPLA specimen while layer thickness had less impact on the tensile strength.

- The interrelationship between the process parameters influencing the tensile strength of the CFRPLA specimen is exhibited in the interaction plot in Figure 17.

- The layer thickness and extruder temperature were directly proportional to each other in terms of tensile strength.

- The layer thickness and extruder speed were inversely proportional to each other in terms of tensile strength.

- The layer thickness and shell thickness were directly proportional to each other in terms of tensile strength. 
- The extruder temperature and extruder speed were inversely proportional to each other in terms of tensile strength.

- The extruder temperature and shell thickness were directly proportional to each other in terms of tensile strength.

- The extruder speed and shell thickness were directly proportional to each other in terms of tensile strength.

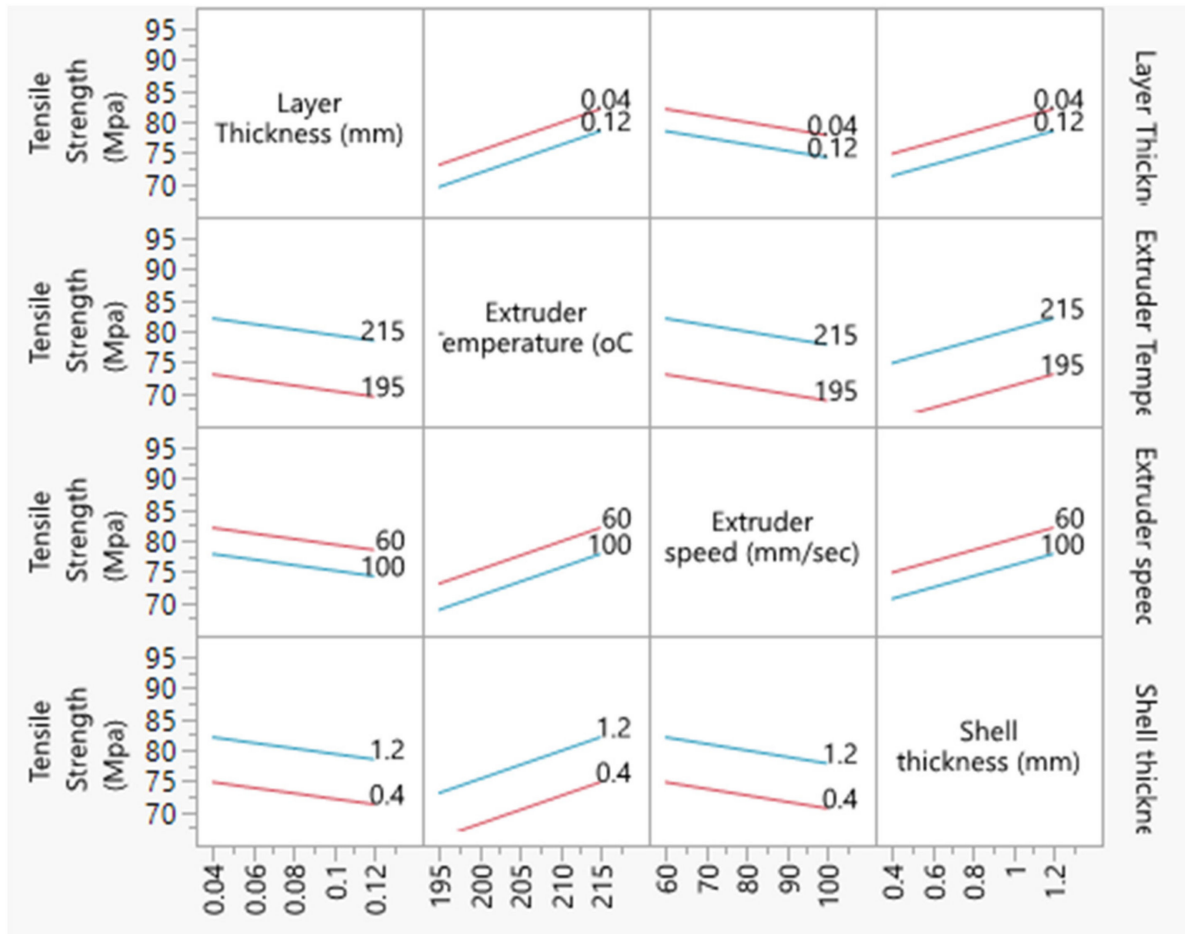

Figure 17. Interaction plot.

From the experimental results, the maximum tensile strength of $78.8 \mathrm{MPa}$ was obtained by maintaining the optimum process parameters values, i.e., layer thickness of $0.06 \mathrm{~mm}$, extruder temperature of $210^{\circ} \mathrm{C}$, extruder speed of $60 \mathrm{~mm} / \mathrm{s}$, and shell thickness of $1.2 \mathrm{~mm}$. From the desirability plot shown in Figure 18, the maximum tensile strength that could be obtained was $82.03 \mathrm{MPa}$ using the following process parameters values: layer thickness of $0.04 \mathrm{~mm}$, extruder temperature of $215^{\circ} \mathrm{C}$, extruder temperature of $60{ }^{\circ} \mathrm{C}$, and shell thickness of $1.2 \mathrm{~mm}$. It was observed that maintaining a minimum layer thickness and increasing the number of layers increased the density and also enhanced the bonding strength between the layers of PLA. The maximum extruder temperature of $215^{\circ} \mathrm{C}$ and the minimum extruder speed of $60 \mathrm{~mm} / \mathrm{s}$ increased the curing time and stabilized the printed layer in order to receive further material deposition over it. The maximum shell thickness of $1.2 \mathrm{~mm}$ provided protection against external loads over the printed layers, which maximized the tensile strength of CFRPLA. 


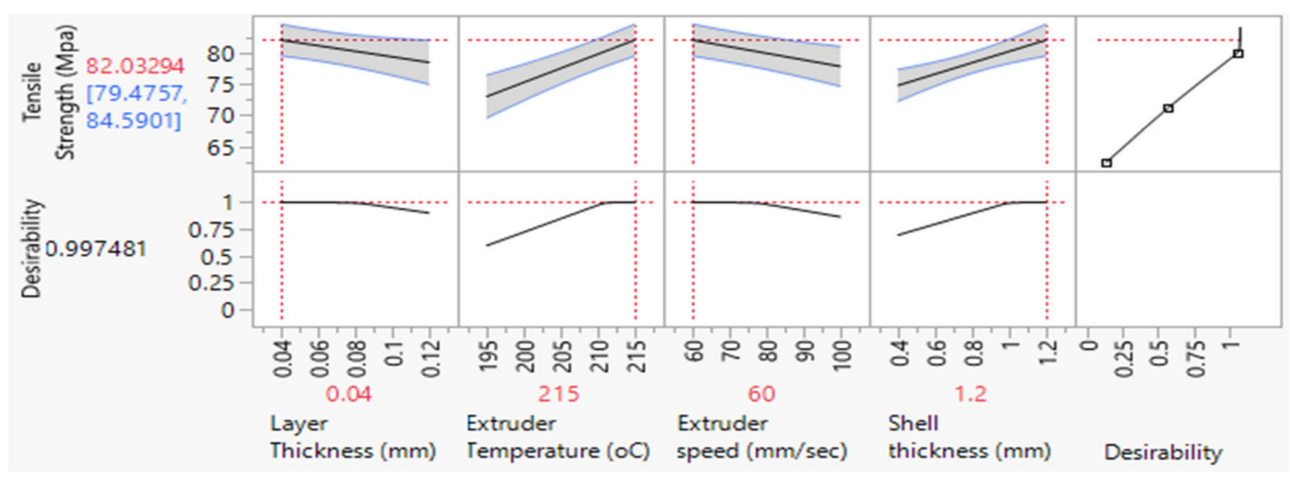

Figure 18. Desirability plot.

\section{Conclusions}

The ultimate aim of this work was to maximize the tensile strength of FDM-processed PLA with a solid CF rod. The following process parameters were identified to obtain the maximum tensile strength of $82.06 \mathrm{MPa}$ : layer thickness of $0.04 \mathrm{~mm}$, extruder temperature of $215^{\circ} \mathrm{C}$, extruder speed of $60 \mathrm{~mm} / \mathrm{s}$, and shell thickness of $1.2 \mathrm{~mm}$. The results clearly showed that the tensile strength of bioinspired solid CFRPLA FDM components were high compared to pure PLA 3D printed components. The results revealed that the tensile strength of pure PLA was $28 \mathrm{MPa}$, whereas the tensile strength of 3D printed CFRPLA specimen with optimized parameters was $82.06 \mathrm{MPa}$. This was approximately three times higher compared to pure PLA, indicating a drastic improvement. Future studies will be carried out to determine other mechanical characteristics, such as flexural strength, impact strength, and wear behavior of CFRPLA.

Author Contributions: Conceptualization, A.S.; Formal analysis, A.S.; Investigation, A.S. and R.W.; Resources, R.W.; Supervision, S.M. and R.V.; Writing-original draft, A.S. and R.W.; Writingreview \& editing, S.M., R.V. and B.S. All authors have read and agreed to the published version of the manuscript.

Funding: This research received no external funding.

Conflicts of Interest: The authors declare no conflict of interest.

\section{References}

1. Additive Manufacturing: Opportunities and Constraints. Available online: https://www.raeng.org.uk/publications/reports / additive-manufacturing (accessed on 23 May 2013).

2. Rajkumar, V.; Felix, R.; Sarat, S. 3D printing technologies and composite materials for structural applications. In Green Composites for Automotive Applications, 1st ed.; Georgios, K., Arlindo, S., Eds.; Woodhead Publishing: Cambridge, UK, 2019 ; pp. 171-196.

3. Khaled, G.M.; Carlo, M.; Ahmed Jawad, Q. Strength to cost ratio analysis of FDM Nylon 12 3D Printed Parts. Procedia Manuf. 2018, 26, 753-762.

4. Rajkumar, V.; Nahaad Mohammed, V.; Chadurvedi, V.; Felix, R.; Murali, K. Experimental Investigation on Fabrication of Thermoset Prepreg Composites Using Automated Fibre Placement Process and 3D Printed Substrate; Procedia CIRP: Amsterdam, The Netherlands, 2019; Volume 85, pp. 296-301.

5. Liu, Z.; Wang, Y.; Wu, B. A critical review of fused deposition modeling 3D printing technology in manufacturing PLA parts. Int. J. Adv. Manuf. Technol. 2019, 102, 2877-2889. [CrossRef]

6. Cicala, G.; Giordano, D.; Tosto, C.; Filippone, G.; Recca, A.; Blanco, I. Polylactide (PLA) Filaments a Biobased Solution for Additive Manufacturing: Correlating Rheology and Thermomechanical Properties with Printing Quality. Materials 2018, 11, 1191. [CrossRef] [PubMed]

7. Karsli, N.G.; Aytac, A. Tensile and thermo mechanical properties of short carbon fiber reinforced polyamide 6 composites. Compos. Part B Eng. 2013, 51, 270-275. [CrossRef]

8. Blanco, I. The Use of Composite Materials in 3D Printing. J. Compos. Sci. 2020, 4, 42. [CrossRef]

9. Zhong, W.; Li, F.; Zhang, Z.; Song, L.; Li, Z. Short fiber reinforced composites for fused deposition modelling. Mater. Sci. Eng. A-Struct. 2001, 301, 125-130. [CrossRef] 
10. Hao, W.; Liu, Y.; Zhou, H.; Chen, H.; Fang, D. Preparation and characterization of 3D printed continuous carbon fiber reinforced thermosetting composites. Polym. Test. 2018, 65, 29-34. [CrossRef]

11. Shofner, M.L.; Lozano, K.; Rodríguez-Macías, F.J.; Barrera, E.V. Nanofiber-reinforced polymers prepared by fused deposition modeling. J. Appl. Polym. Sci. 2003, 89, 3081-3090. [CrossRef]

12. Standard Terminology for Additive Manufacturing Technologies. West Conshohocken: ASTM International. 2012. Available online: https: / / www.astm.org/Standards/F2792.htm (accessed on 31 December 2020).

13. Hao, W.; Ge, D.; Ma, Y.; Yao, X.; Shi, Y. Experimental investigation on deformation and strength of carbon/epoxy laminated curved beams. Polym. Test. 2012, 31, 520-526. [CrossRef]

14. Hao, W.; Yuan, Y.; Zhu, J.; Chen, L. Effect of impact damage on the curved beam interlaminar strength of carbon/epoxy laminates. J. Adhes. Sci. Technol. 2016, 30, 1189-1200. [CrossRef]

15. Ruban, W.; Vijayakumar, V.; Dhanabal, P.; Pridhar, T. Effective process parameters in selective laser sintering. Int. J. Rapid Manuf. 2014, 4, 148-164. [CrossRef]

16. Zeng, W.L.; Guo, Y.L.; Jiang, K.Y.; Yu, Z.X.; Liu, Y.; Shen, Y.D. Laser intensity effect on mechanical properties of Wood-Plastic composite parts fabricated by selective laser sintering. J. Thermoplast. Compos. 2012, 26, 125-136. [CrossRef]

17. Gray, W.; Baird, D.G.; Bøhn, J.H. Thermoplastic composites reinforced with long fiber thermotropic liquid crystalline polymers for fused deposition modelling. Polym. Compos. 1998, 19, 383-394. [CrossRef]

18. Fischer, A.; Rommel, S.; Bauernhansl, T.; Kovács, G.; Kochan, D. New Fiber Matrix Process with 3D Fiber Printer-A Strategic In-process Integration of Endless Fibers Using Fused Deposition Modeling (FDM). IFIP Adv. Inf. Commun. Technol. 2013, 411, 167-175.

19. Melenka, G.W.; Cheung, B.K.O.; Schofield, J.S.; Dawson, M.R.; Carey, J.P. Evaluation and prediction of the tensile properties of continuous fiber-reinforced 3D printed structures. Compos. Struct. 2016, 153, 866-875. [CrossRef]

20. Susanne, C.; Martin, S.; Elke, V.; Jurgen, G.; Uwe, G. Fiber reinforcement during 3D printing. Mater. Lett. 2015, 139, 165-168.

21. Nanya, L.; Li, Y.; Liu, S. Rapid prototyping of continuous carbon fiber reinforced polylacticacid composites by 3D printing. J. Mater. Process. Technol. 2016, 238, 218-225.

22. Cwikla, G.; Grabowik, C.; Kalinowski, K.; Paprocka, I.; Ociepka, P. The influence of printing parameters on selected mechanical properties of FDM/FFF 3D-printed parts. Mater. Sci. Eng. 2017, 227, 012033.

23. Ning, F.; Cong, W.; Hu, Y.; Wang, H. Additive manufacturing of carbon Fiber-reinforced plastic composites using fused deposition modeling: Effects of process parameters on tensile properties. J. Compos. Mater. 2017, 51, 451-462. [CrossRef]

24. Farzad, R.; Godfrey, C.O. Fused deposition modelling (FDM) process parameter prediction and optimization using group method for data handling (GMDH) and differential evolution (DE). Int. J. Adv. Manuf. Technol. 2014, 73, 509-519.

25. Tian, X.; Liu, T.; Yang, C.; Wang, Q.; Li, D. Interface and performance of 3D printed continuous carbon fiber reinforced PLA composites. Compos. Part A 2016, 88, 198-205. [CrossRef]

26. Lin, E.; Li, Y.; Ortiz, C.; Boyce, M.C. 3D printed, bio-inspired prototypes and analytical models for structured suture interfaces with geometrically-tuned deformation and failure behaviour. J. Mech. Phys. Solids 2014, 73, 166-182. [CrossRef]

27. Huang, B.; Meng, S.; He, H.; Jia, Y.; Xu, Y.; Huang, H. Study of Processing Parameters in Fused Deposition Modeling Based on Mechanical Properties of Acrylonitrile-Butadiene-Styrene Filament. Polym. Sci. Eng. 2019, 59, 120-128. [CrossRef]

28. Padzi, M.M.; Bazin, M.M.; Muhamad, W.M.W. Fatigue Characteristics of 3D Printed Acrylonitrile Butadiene Styrene (ABS). Mater. Sci. Eng. 2017, 269, 012060. [CrossRef]

29. Zhao, H.; Liu, X.; Zhao, W.; Wang, G.; Liu, B. An Overview of Research on FDM 3D Printing Process of Continuous Fiber Reinforced Composites. J. Phys. Conf. Ser. 2019, 1213, 052037. [CrossRef]

30. Wu, J. Study on optimization of 3D printing parameters. Mater. Sci. Eng. 2018, 392, 062050. [CrossRef]

31. Srinivasan, R.; Ruban, W.; Deepanraj, A.; Bhuvanesh, R.; Bhuvanesh, T. Effect on infill density on mechanical properties of PETG part fabricated by fused deposition modelling. Mater. Today Proc. 2020, 1-5. [CrossRef]

32. Srinivasan, R.; Pridhar, T.; Ramprasath, L.S.; Sree Charan, N.; Ruban, W. Prediction of tensile strength in FDM printed ABS parts using response surface methodology (RSM). Mater. Today Proc. 2020, 1-6. [CrossRef]

33. Srinivasan, R.; Nirmal Kumar, K.; Jenish Ibrahim, A.; Anandu, K.V.; Gurudhevan, R. Impact of fused deposition process parameter (infill pattern) on the strength of PETG part. Mater. Today Proc. 2020, 1-5. [CrossRef]

34. Selvam, A.; Mayilswamy, S.; Whenish, R. Strength improvement of additive manufacturing components by reinforcing carbon fiber and by employing bioinspired interlock sutures. J. Vinyl Addit. Technol. 2020, 1-13. [CrossRef]

35. Dey, A.; Yodo, N. A Systematic Survey of FDM Process Parameter Optimization and Their Influence on Part Characteristics. J. Manuf. Mater. Process. 2019, 3, 64. [CrossRef]

36. Martin, J.; Fiore, B.; Erb, R. Designing bioinspired composite reinforcement architectures via 3D magnetic printing. Nat. Commun. 2015, 6, 8641. [CrossRef] [PubMed]

37. Zhang, Y.; Yao, H.; Christine, O.; Xu, J.; Dao, M. Bio-inspired interfacial strengthening strategy through geometrically interlocking designs. J. Mech. Behav. Biomed. Mater. 2012, 15, 70-77. [CrossRef] [PubMed] 